\title{
NARRATIVAS SOBRE AS TRAJETÓRIAS DE PROFISSIONAIS DE SERVIÇOS DE SAÚDE MENTAL INFANTOJUVENIL
}

\author{
NARRATIVES ABOUT THE BACKGROUNDS OF PROFESSIONALS PROVIDING CHILDHOOD \\ AND ADOLESCENT MENTAL HEALTH CARE SERVICES
}

\section{NARRATIVAS SOBRE LAS TRAYECTORIAS DE PROFESIONALES DE SERVICIOS DE SALUD MENTAL PARA NIÑOS Y ADOLESCENTES}

\author{
Camila Junqueira Muylaert ${ }^{1}$ \\ Modesto Leite Rolim Neto ${ }^{2}$ \\ Fabiola Zioni ${ }^{3}$ \\ Vicente Sarubbi Junior ${ }^{4}$ \\ Alberto Olavo Advincula Reis ${ }^{5}$
}

Resumo Esta pesquisa exploratória, de natureza qualitativa, teve como foco a narrativa dos profissionais de Centros de Atenção Psicossocial infantojuvenis. O objetivo foi descrever e analisar as trajetórias de trabalhadores desses centros e suas relações com o processo de inserção e prática nesse campo, bem como compreender como essa trajetória influencia na atuação cotidiana dos profissionais. Utilizou-se um questionário com perguntas abertas e entrevistas narrativas. O universo do estudo compreendeu oito trabalhadores de diferentes categorias profissionais, lotados em dois centros de atenção psicossocial infantojuvenis no município de São Paulo, Brasil, um gerenciado diretamente pela prefeitura e o outro, por uma organização social de saúde. Evidenciou-se que a vida política pouco é citada pelos trabalhadores da organização, enquanto para os profissionais da prefeitura representa um importante sentido do trabalho. Todos os profissionais entrevistados guardam semelhanças entre si, dentre as quais: a assimilação do tratamento ofertado às crianças aos cânones adultos, a passagem por hospitais e consultórios em suas trajetórias e o foco do olhar do profissional dirigido à doença e não ao sujeito do sofrimento. Presos nessas representações, os profissionais vivem competências, habilidades e pensamentos que dão origem à improvisação e à angústia.

Palavras-chave saúde pública; saúde mental; infância e adolescência; assistência à saúde.
Abstract This qualitative exploratory study focused on the narrative of professionals working at Childhood and Adolescent Psychosocial Care Centers. The goal was to describe and analyze the backgrounds of the staff of these centers and their relationship to the process of insertion and practice in this field, as well as to understand how these backgrounds influence these professionals' everyday work. A questionnaire with open questions and narrative interviews were used. The total study population comprised eight workers from different professional categories working at two childhood and adolescent psychosocial care centers in the city of São Paulo, state of São Paulo, Brazil, one managed directly by the city, while the other by a social health organization. It was shown that politics is not often cited by the organization's employees, while for city professionals is an important part of the meaning of their work. All respondents bear similarities, among which the assimilation of the treatment offered to children based on adult rules, having worked at hospitals and clinics, and the professional's focus on the disease, not the subject of the suffering. Captive of these representations, these professionals experience competencies, skills, and thoughts that give rise to improvisation and anguish.

Keywords public health; mental health; childhood and adolescence; health care. 


\section{Introdução}

Os Centros de Atenção Psicossocial infantojuvenis (CAPSis) representam atualmente a principal instituição de cuidado às crianças e adolescentes em sofrimento psíquico. Tais instituições seguem o paradigma da reforma psiquiátrica que se contrapõe ao modo asilar de tratamento e aos saberes a ele assemelhados. A reforma tem entre seus objetivos envolver o sujeito em seu sofrimento e nos eventos psíquicos de que ele se queixa. Incluir a criança ou o adolescente como sujeito, com suas peculiaridades e responsabilidades sobre o curso de sua existência, dando voz e escuta a eles, é o único modo de garantir que não se reproduza na sua assistência o ato de discursar sobre eles (Brasil, 2005).

Como indicam Reis et al. (2010), esses avanços no entendimento e nas ações de saúde mental infantojuvenil ocorreram apesar do 'pesado' legado: a saúde mental infantojuvenil no Brasil e no mundo, durante muitos anos foi vista como menos importante que a saúde mental dos adultos e por isso recebeu menos investimento. Tal fato se deu em parte devido às diferentes visões que a sociedade teve a respeito da criança e do adolescente ao longo da história.

Reis et al. (2010), ao traçarem um histórico da saúde mental infantojuvenil, afirmam que o conceito de infância apareceu após a Revolução Francesa, e o de adolescência, após a Primeira Guerra Mundial. Antes disso pouca atenção era dada à saúde mental das crianças e adolescentes. Essa dimensão histórico-social explica diversas características do trabalho neste campo. Não é raro que profissões que envolvam o cuidado sejam desvalorizadas e historicamente alocadas ao feminino. O cuidado se encontra, amiúde, associado às mulheres, mães ou cuidadoras e instituições religiosas.

Nesse sentido, o acolhimento de crianças e adolescentes em sofrimento mental deu-se, primeiro, por meio de ofertas de tratamento de cunho caritativo e filantrópico. O tratamento de adultos centralizava-se nas mãos das santas casas da misericórdia e de setores conservadores do clero até que os médicos passaram a aspirar ao reconhecimento do Estado para legitimar a assistência psiquiátrica, reivindicando um projeto científico de assistência e poder institucional (Amarante, 1994).

Com o sucesso dessas reivindicações, houve uma expansão dos manicômios pelo país, então organizados segundo uma concepção positivista, organicista e segregacionista do transtorno mental, tendo como modelo o tratamento moral destinado a reformar o paciente. A vinculação da saúde mental à medicina fixou a prática clínica e a internação hospitalar como principais recursos para lidar com pessoas em sofrimento psíquico (Reis et al., 2010). 
A reforma psiquiátrica trouxe um novo paradigma de tratamento propondo uma rede substitutiva ao modelo manicomial, visando à inserção social do sujeito em sofrimento psíquico. A presença da família, da comunidade e o ensejo de profissionais engajados a exercerem suas funções de modo mais reflexivo se constituíram como uma proposta desafiadora para um novo modelo de tratamento na área de saúde mental.

Dessa forma, no tocante aos aspectos mais específicos do trabalho no âmbito das atividades cotidianas para as quais são convocados os profissionais da saúde mental, suas histórias de vida têm impacto considerável. Essas histórias que pertencem aos sujeitos devem ser apreendidas, antes de tudo, pelo seu próprio discurso no qual se encontra implicado.

Essas considerações justificam, consequentemente, a intenção de se investigar as características do trabalho dos profissionais de saúde mental infantojuvenil em conexão com suas trajetórias de vida, recorrendo, para tanto, às narrativas por eles produzidas. O processo de formar profissionais para atuar na área de saúde mental deve ir muito além dos recursos tradicionais da educação.

A escassez de estudos sobre o tema, aliada à sua importância como base para a transformação das práticas no âmbito das novas orientações voltadas à saúde mental motivam a análise das trajetórias de trabalhadores e justificam este artigo.

Dessa maneira, o objetivo deste estudo foi descrever e analisar as trajetórias de trabalhadores de CAPSis e suas relações com o processo de inserção e prática nesse campo, bem como compreender como essa trajetória influencia na atuação cotidiana dos profissionais.

\section{Método}

\section{Entrevistas narrativas}

Esta pesquisa observacional, exploratória, de natureza qualitativa, teve como foco as narrativas de profissionais de CAPSis. Utilizou-se um questionário com perguntas abertas e entrevistas narrativas. O instrumento visou a obter os dados necessários para se tecer um perfil dos trabalhadores, com as características gerais de suas formações profissionais, assim como para complementar e fornecer pistas para a condução das narrativas.

As entrevistas narrativas são instrumentos voltados à reconstrução dos acontecimentos sociais do ponto de vista dos informantes, com o objetivo de compreender os contextos sociais em que as biografias foram construídas e os fatores que produzem mudanças e motivam as ações dos informantes 
(Jovchelovich e Bauer, 2002). Assim, abordar as narrativas como método pressupõe não apenas entendê-las como uma listagem de acontecimentos, mas também identificar os sentidos a eles alocados.

As entrevistas narrativas são técnicas para gerar histórias (Lira, Catrib e Nations, 2003). Sua utilização para abordar o tema desta investigação não é frequente na literatura e não se atrela a um referencial teórico específico. Dessa forma, o quadro teórico adotado foi construído utilizando-se diferentes autores que dialogam entre si (Bachelard, 1996; Vasconcelos, 2013; Bourdieu, 2011), ao que se agregaram os conceitos que subjazem ao modo de atenção psicossocial e à reforma psiquiátrica.

Para a sistematização e organização dos dados empregou-se a proposta de Shutze descrita por Jovchelovich e Bauer (2002): transcrição na íntegra das entrevistas e detalhamento das expressões verbais; divisão do texto em material indexado (individual) e não indexado (coletivo); agrupamento e identificação das trajetórias individuais e estabelecimento de semelhanças e identificação das trajetórias coletivas. As unidades de significação possibilitaram a construção de categorias que foram agrupadas em núcleos de significado. Alguns desses núcleos tiveram significância em termos de representatividade e frequência temática. Neste artigo, que é parte da dissertação de mestrado Formação, vida profissional e subjetividade: narrativas de trabalhadores de Centro de Atenção Psicossocial Infantojuvenil, da primeira autora, são discutidos os núcleos: a escolha profissional, a trajetória dos profissionais e o contexto social das escolhas.

O universo do estudo compreendeu oito trabalhadores, de diferentes categorias profissionais (médico, psicólogo, terapeuta ocupacional, enfermeiro e auxiliar de enfermagem) de ambos os sexos, lotados em dois CAPSis no município de São Paulo, Brasil. Os profissionais do CAPSi gerenciado pela organização social de saúde (OSS) foram codificados como S1, S2 S3 e S4, e os profissionais do CAPSi gerenciado pela prefeitura, S5, S6, S7 e S8.

O critério de escolha das unidades foi a inserção dessas instituições no processo da reforma psiquiátrica, determinada tanto pela sua posição histórica como pela proximidade com os princípios emanados do modo de atenção psicossocial. Buscou-se, assim, um CAPSi gerenciado diretamente pela prefeitura e um outro gerenciado por uma OSS. Na escolha dos profissionais teve-se o cuidado de se contemplar a maior diversidade de categorias profissionais.

A pesquisa, aprovada pelo Comitê de Ética da Faculdade de Saúde Pública da Universidade de São Paulo (CAAE: 01829512.8.0000.5421), teve o sigilo e a participação voluntária dos sujeitos garantidos mediante termo de consentimento livre e esclarecido. 


\section{Resultados e discussão}

\section{As trajetórias profissionais e o atual modelo de saúde mental}

O contexto de atuação profissional no campo da saúde mental é caracterizado por uma série de elementos, muitos dos quais pertencem a uma tradição relativamente antiga e, por essas circunstâncias, constituem-se como históricos. Dentre esses elementos podem-se citar: a trajetória clínica dos profissionais; o foco do cuidado direcionado à doença e não ao sujeito; as influências que a saúde mental infantojuvenil sofre da área da educação e do tratamento dado aos adultos. Muitos desses elementos estão registrados nas falas oriundas das entrevistas narrativas realizadas.

Observa-se que muitos profissionais entrevistados tinham somente experiências em saúde mental de adultos e, entre os que tinham trabalhado com crianças, as experiências restringiam-se à área da educação.

Eu terminei a faculdade, trabalhei com inclusão em escola, e com consultório também (...) trabalhei com inclusão um pouco, mas estava já querendo sair do ambiente escolar, porque acho que é muito limitado o trabalho do psicólogo ainda difícil, muita resistência de trabalhar com saúde mental nas escolas, eu comecei a cansar e procurar mais na área da saúde mesmo e vi a vaga e passei (S3).

Eu já tinha trabalhado em consultório, no convênio, atendendo paciente adulto (S2).

Acho que eu tive formação pra trabalhar em CAPS [Centro de Atenção Psicossocial] adulto, mas em CAPSi não. Eu vim da educação e a gente trabalhava a infância, com a questão do autismo (S4).

Constata-se, assim, que a saúde mental infantojuvenil ainda está vinculada à educação ou como 'sombra' da saúde mental dos adultos, como em épocas anteriores e supostamente superadas. Além disso, na trajetória dos profissionais, destaca-se um tipo de experiência muito específica e singular: a atuação em hospital e consultório.

$\mathrm{O}$ interesse em trabalhar em CAPS, para muitos profissionais, veio da percepção que há, além dos hospitais, outras possibilidades para lidar com pessoas em sofrimento psíquico, mas para tanto tiveram antes que passar pela experiência hospitalar a qual se pode revestir de aspectos tanto positivos quanto negativos.

Os profissionais entrevistados conheceram, primeiro, os hospitais psiquiátricos, suas lógicas e modus operandi, e só depois entraram em contato 
com o modelo de atenção psicossocial vigente no funcionamento e na lógica de outros equipamentos de saúde mental. O hospital psiquiátrico revelou-se, assim, tanto um importante local de formação no período da graduação ou da pós-graduação dos sujeitos (aspecto positivo) quanto um lugar de experiências a serem refutadas (aspecto negativo):

No estágio em psiquiatria, apesar de ser um hospital psiquiátrico em um esquema bem tradicional de manicômio (...) na psiquiatria no HC [hospital das clínicas] foi a primeira vez que entrei em contato com a saúde mental, com as teorias e apesar de ser bem manicomial, bem psiquiátrico, eles davam uma pincelada no que havia de diferente, comunidades terapêuticas (S6).

E hospital eu não queria trabalhar de jeito nenhum e aí eu fui trabalhar em um ambulatório de especialidades (...) Eu comecei a me interessar bastante pela questão de saúde mental, principalmente comecei a me interessar pelo centro de convivência, onde fui trabalhar e eu fiquei muito interessado pela questão das oficinas terapêuticas, do trabalho mais ampliado, não só trabalho de psicoterapia, de atendimento psicológico, mas trabalho que desenvolvesse uma rede (S8).

Sejam quais forem os significados atribuídos a esse 'local-ponte' representado pelo hospital, é ele que constitui o primeiro emprego de muitos dos entrevistados. O consultório com ou sem convênios, ao lado do hospital, também aparece como o ponto profissional de ancoragem. É nesses dois locais que se dá uma primeira experiência de prática clínica com o vivo do sofrimento mental. É possível pensar, assim, que o imaginário da prática clínica envolvendo a saúde mental é marcado pelas figuras tradicionais da medicina (hospital e consultório) com as quais terapeutas ocupacionais, psicólogos, enfermeiros parecem no início de carreira querer se adornar.

Eu me formei em 1987, já na saúde mental trabalhava em um hospital em Ribeirão Preto, comecei assim, em 97, a gostar mais do psicodrama, fiquei dois anos lá, depois vim pra São Paulo e entrei no HC [hospital das clínicas] na psiquiatria, que era bem diferente do que é hoje a estrutura, fiquei cinco anos lá e trabalhando numa clínica particular, onde eu tinha mais contato com a infância (S8).

O estágio e aprimoramento em hospital, tanto requerido pela instituição de ensino de graduação como pela profusão de situações variadas que a imersão na realidade prática possibilita, têm um papel marcante na vida do profissional. O hospital psiquiátrico se constitui como um marco importante na consecução da carreira dos profissionais entrevistados, quer pelo aspecto simbólico iniciático, quer pela apresentação da diversificação dos fenôme- 
nos humanos pertinentes ao campo da saúde, quer pela possibilidade de se colocar à prova os conhecimentos adquiridos ou requeridos. Seu papel e seu impacto é tão forte e marcante que, tal como se pôde perceber nas diversas falas, o hospital se torna ponto de referência, de comparação, de julgamento tanto em seus aspectos elegiáticos como críticos ao longo da história de vida dos profissionais. A fala a seguir explicita tais considerações:

Quando me ofereceram uma proposta de trabalhar num CAPS adulto, no ano de 2009, foi quando eu conheci a diferença entre hospital e CAPS (...) No cuidado em enfermagem e com a vivência mesmo nos CAPS em São Paulo e eu trabalhava muito a inserção do paciente na sociedade, não deixava ele ficar internado ou restrito num ambiente, o hospital só devia existir mesmo com os CAPS abertos. Eu entrei em outro hospital geral, na ala da enfermagem psiquiátrica e, uma vez tendo tido a experiência de trabalhar em CAPS, me senti muito frustrada; não seria frustrada a palavra, chateada por voltar a uma instituição de cunho fechado e eu percebi que meu objetivo profissional e até pessoal era voltar a trabalhar em CAPS e eu fiquei um mês só no hospital e quando eles iam aprovar minha experiência eu decidi sair; não era isso que eu queria para mim nem para as pessoas; lá no hospital era remédio, banho, muito fechado. Então, eu achava aquilo muito restrito (S1).

É interessante observar que uma vez tendo feita a passagem pelo hospital, para a qual concorrem tanto o desejo pessoal como as injunções da instituição de ensino, os trabalhadores, ao se inserirem em outra realidade de atuação, que é a rede pública de saúde mental substitutiva à lógica hospitalar, conseguem se desfazer do fascínio imaginário que o hospital/consultório exercia sobre eles.

Os hospitais/consultórios apresentam-se como dispositivos iniciais de inserção na prática profissional voltada à saúde mental e, em seguida, são superados como quadro de referência (imaginário e simbólico), pela descoberta e pela atuação na rede substitutiva de saúde mental. Entretanto, há de se observar, que, até por força da formação recebida na graduação, sua lógica permanece como habitus, tal como postulado por Bourdieu (2011), infiltrando-se, produzindo contradições, equívocos e instabilidades na própria representação da atuação profissional nos CAPSis.

O conceito de habitus que ele desenvolverá ao longo de sua obra corresponde a uma matriz, determinada pela posição social do indivíduo que lhe permite pensar, ver e agir nas mais variadas situações. O habitus traduz, dessa forma, estilos de vida, julgamentos políticos, morais, estéticos. Ele é também um meio de ação que permite criar ou desenvolver estratégias individuais ou coletivas (Vasconcelos, 2002, p. 79). 
A passagem dos profissionais pelos hospitais, escolas ou consultórios antes de chegar aos CAPSis pode ser pensada como situação equivalente às inércias ou aos obstáculos epistemológicos no sentido que Bachelard emprestou a esses termos:

Quando se procuram as condições psicológicas do progresso da ciência, logo se chega à convicção de que é em termos de obstáculos que o problema do conhecimento científico deve ser colocado. E não se trata de considerar obstáculos externos, como a complexidade e a fugacidade dos fenômenos, nem de incriminar a fragilidade dos sentidos e do espírito humano: é no âmago do próprio ato de conhecer que aparecem, por uma espécie de imperativo funcional, lentidões e conflitos. É aí que mostraremos causas de estagnação e até de regressão, detectaremos causas de inércia às quais daremos o nome de obstáculos epistemológicos. O conhecimento do real é luz que sempre projeta algumas sombras. Nunca é imediato e pleno. (Bachelard, 1996, p.10).

De fato, tal como pode ser exemplificado na fala a seguir, os trabalhadores comparam a clínica do consultório com a clínica que realizam nos CAPSis, como se fosse possível transpor a clínica que se realiza no consultório para os CAPSis, o que seria uma extensão do consultório para o ambiente institucional:

É difícil falar, porque tudo muda na atuação. Na faculdade você aprende um setting terapêutico $x$ e na prática não é bem assim, tem uma sala diferente, tem limites que mudam um pouco o que você gostaria de fazer, ou o que seria ideal. Então, isso vai influenciando em como você vai trabalhar, tem milhares de problemas, tanto o lugar, o espaço físico, os profissionais que você trabalha junto, a demanda dos pacientes, não sei na verdade, tudo muda muito o jeito de atuar, a agenda e o jeito que ela é feita, o tempo que a gente tem para atender, o tempo que a gente tem para pensar sobre, o número de pacientes que a gente tem, então, se tivesse supervisão as coisas seriam diferentes, se tivesse espaço diferente também seria diferente (S3).

O profissional que estava preparado para atuar especificamente na clínica do consultório, ao se defrontar com a realidade dos CAPSis, percebe que seus recursos são insuficientes e não se aplicam a essa realidade. $\mathrm{O}$ ambiente não é propício a tal exercício e não há estrutura (nem física nem de mão de obra), além da demanda ser bastante diferente da demanda de uma clínica particular.

Outro aspecto que chama a atenção nas falas exploradas é o desconhecimento por partes dos profissionais do que é uma criança saudável. Em termos mais precisos, o foco do olhar do profissional se encontra na 'doença', 
no 'transtorno', no atributo da pessoa que sofre e não na saúde mental ou na pessoa do sujeito do sofrimento. É importante ressaltar que os CAPSis são voltados, prioritariamente, à atenção de crianças e adolescentes em sofrimento psíquico. Não se espera, portanto, que a atuação seja dirigida ao público cujas queixas não se configuram dessa forma ou nessa intensidade. Entretanto, esse desconhecimento revela certa tendência presente na atuação do profissional que a condiciona a ser focada no 'desvio', na 'anormalidade', no 'excepcional', numa determinada condição apresentada pelo adolescente ou pela criança.

E eu tinha conhecimento do que era uma criança com problemas, eu não tinha ideia do que era uma criança normal e achei muito interessante e aproveitei os quatro anos que eu estava lá para aprender mais sobre essas crianças. Fiz até uns cursos nessa época buscando como era o desenvolvimento de uma criança normal por conta (S6).

Nesse sentido, Nunes, Jucá e Valentim (2007) indicam que há uma singularidade paradigmática no campo da saúde mental. Para eles fica visível o exílio ou a alienação desta área em que hospitais e ambulatórios psiquiátricos foram construídos separados dos hospitais e ambulatórios gerais. Esse apartamento da saúde mental faz com que os trabalhadores fiquem isolados, aumentando a dificuldade em trabalhar com o que preconiza a reforma psiquiátrica: romper com o olhar patologizante ao sujeito em sofrimento psíquico.

A reforma psiquiátrica propõe novas formas de relacionamento entre profissionais e usuários dos serviços, entre profissionais e o território, assim como entre os profissionais de saúde. Buscando a inserção social do sujeito como cidadão de direitos e deveres, a reforma psiquiátrica enfatiza a importância da subjetividade de todos os envolvidos, inclusive os profissionais.

Ainda Nunes, Jucá e Valentim (2007) observaram, em entrevistas com trabalhadores de saúde mental, que a maioria deles se sente despreparada para o manejo com pessoas em sofrimento psíquico, e angustiada por lidar com situações difíceis que a saúde mental envolve. Desejam qualificar-se, nesse campo, por sentirem que estariam descumprindo a ética do cuidar.

Segundo Marazina (1989), assim como os loucos são colocados à margem da sociedade e da cultura, a produção de trabalhadores da saúde mental também é representada e vivida como marginalizada, pois tenta responder a uma demanda para a qual seu saber restrito não se mostra suficiente, uma vez que a saúde mental vai muito além de seu campo adstrito, pois envolve o domínio político, social, econômico, dentre outros.

Essa discussão vai ao encontro do postulado por Amarante (2000) quando discute os limites do saber do profissional ou o conhecimento espe- 
cializado alienante. Dessa forma, o saber tradicional vê-se preso em uma contradição infindável: como resgatar o sujeito de sua alienação a partir de um saber alienado?

Desde o século XVIII, o termo alienado é usado para definir a loucura, esse termo vem de alienígena, estrangeiro, quer dizer aquilo que está fora de si. Partindo dessa compreensão, Marazina (1989) questiona a tarefa do trabalhador de saúde mental de tratar alienados, já que seu próprio trabalho está inserido num modelo econômico que produz trabalho alienado e alienação.

Diante desse contexto, o desafio do trabalho na área da saúde mental revela-se ainda maior por ser uma atividade inclusiva, de cuidados e solidariedade que envolve relações humanas e trabalho em equipe em um mundo capitalista, individualista que estimula relações de competitividade.

Observa-se que uma das formas citadas especificamente pelos trabalhadores da prefeitura para lidar com as angústias vivenciadas diariamente pelos trabalhadores de CAPSis é a militância, assim como a luta sindical.

Pra amenizar minha angústia e minha insatisfação eu fui buscar, eu fui num caminho da luta sindical; por conta disso, pelo menos eu estou lá tentando fazer alguma coisa, não é muito meu estilo, mas eu sempre estive lá no meio, tentando fazer algo (...) Era uma prefeitura, na época do PSDB, mas a secretaria de saúde era do PCB e isso fazia uma diferença muito grande (S6).

A militância tem um papel em meu jeito de viver e a forma de seguir (S5).

Diferentemente, os profissionais da OSS tendem a lidar com as dificuldades do trabalho e com a baixa remuneração, realizando outras atividades, incluindo outro emprego. Nos questionários constata-se que entre os quatro profissionais da prefeitura apenas um tem outro emprego além do CAPSi, enquanto três dos quatro profissionais da OSS têm outra atividade remunerada.

Quando eu fui trabalhar com gerência, foi uma coisa que fez muita diferença, não é técnico, né? Foi bom pra mim, tem sido bom pra mim, nesse sentido que eu consigo trabalhar com outras partes da minha mente, do meu cérebro, coisas que eu não uso normalmente, acho que é uma coisa da saúde mental, vejo que muitas pessoas fazem isso, a cada dois anos mudam de tipo, continuam na saúde mental, mas mudam o tipo, ou fazem várias coisas ao mesmo tempo, tem consultório e trabalha em instituição, é professor, acho que é uma coisa que alivia, acho importante. Ficar numa instituição só ou em dois CAPS, por exemplo, é muito maçante (S2).

Atualmente eu tenho dois trabalhos em CAPSi e acho que fica muito corrido; na verdade, acho que conciliar dois trabalhos foi por uma questão financeira, mas 
também pela angústia desse outro trabalho; quando eu vim fazer entrevista nesse CAPS, acho que vim talvez com a intenção de deixar o outro trabalho, mas me pareceu interessante conciliar as duas coisas (S4).

Observa-se que os profissionais das OSS não relataram em seus discursos forma alguma de militância, luta política e sequer citaram questões partidárias, como se isso não tocasse seus trabalhos, e talvez não toque. Pode-se aventar a possibilidade de eles manterem-se distantes e menos atentos às questões políticas quando comparados aos profissionais da prefeitura, uma vez que seu empregador é uma instituição terceirizada e quem lida com as instâncias governamentais mantém-se longe de seus cotidianos. Além disso, o momento em que os profissionais da OSS se interessaram pela saúde mental é bastante diferente do momento em que os profissionais da prefeitura o fizeram. Assim,

\begin{abstract}
A formação de recursos humanos é outro desafio fundamental. A maior parte dos novos profissionais da rede é formada de jovens que não passaram pelo processo de luta política e ideológica que envolveu a criação do movimento antimanicomial, não viveram o intenso intercâmbio com figuras emblemáticas desse movimento no nível internacional, como Basaglia, Foucault, Rotelli e outros, em suas vindas ao Brasil. Boa parte desses profissionais se tornou adulta num momento da vida do país em que as grandes bandeiras de transformação política já tinham se tornado história, momento em que a própria esfera da política começou a experimentar um esvaziamento que só fez se acentuar desde então (Bezarra, 2007, p. 2).
\end{abstract}

Portanto, o trabalho em saúde mental no âmbito da atenção psicossocial envolve uma dimensão social, em que não basta um conhecimento técnico/específico dos trabalhadores, mas um conhecimento amplo que englobe o trabalho extramuros institucionais. Nesse sentido, Hirdes e Kantorski (2004) ressaltam que excelentes projetos de reabilitação psicossocial envolvem a preservação e o resgate da história das pessoas envolvidas. Mais do que reabilitar as pessoas, é necessário que haja a reabilitação do contexto, "entendendo-se que este flui na sua totalidade para a não institucionalização" (Hirdes e Kantorski, 2004, p. 218) para que seja possível, segundo as autoras, a prática de uma reabilitação dentro do setting real da vida das pessoas.

\title{
Considerações finais
}

Os profissionais de CAPSis se formam principalmente em hospitais psiquiátricos de adultos ou em consultórios que representam também seus 
primeiros ambientes de atuação. Portanto, a prática hospitalar e de consultório ainda é um modelo de forte influência na saúde mental infantojuvenil pública e marca de modo importante a formação e a trajetória profissional desses trabalhadores.

Tais instituições se tornam pontos de referência, embora estejam orientadas por lógicas diferentes daquelas que regem o trabalho nos CAPSis, determinando assim a produção de contradições, equívocos e instabilidades na própria representação do exercício profissional nos CAPSis. Seria, portanto, imprescindível que houvesse discussões constantes capazes de realizar aggiornamentos [atualizações] para a atuação dos profissionais nos CAPSis, pois não é fácil a tarefa de transformar anos de aprendizado e formação.

Tendo superado os encantamentos imaginários da atuação em hospital/consultório, cuja lógica está voltada para atendimentos particulares e individualizados, o profissional descobre, nos equipamentos substitutivos, uma nova realidade que lhe é satisfatória. Entretanto, ao se encontrar preso aos conceitos e pensamentos que fundaram sua formação acadêmica, não consegue gestar novas maneiras de pensar e de atuar no front do sofrimento psíquico. Resta-lhe, consequentemente, viver nesse ambiente misto em que a escolha profissional satisfatória se infiltra de elementos de insatisfação.

A militância pouco é citada pelos trabalhadores da OSS, enquanto para os da prefeitura a vida política representa um importante sentido do trabalho. Isso pode ser explicado pelo contexto em que os profissionais da prefeitura se formaram ou se desenvolveram, quando a luta antimanicomial estava em ebulição.

A despeito dessa diferença entre os profissionais da OSS e os da prefeitura, ainda hoje há características no campo da saúde mental infantojuvenil muito semelhantes ao passado, tais como as fortes influências do tratamento dado aos adultos, que foi o campo que a originou, e o foco do olhar do profissional dirigido à 'doença' e não à saúde mental ou ao sujeito do sofrimento. Presos nessas representações, os profissionais vivenciam sentimentos de angústia e, muitas vezes, têm que improvisar em suas práticas cotidianas, uma vez que a realidade atual dos serviços não corresponde aos aprendizados que tiveram em sua trajetória.

Assim, para lidar com a complexidade da saúde mental infantojuvenil em consonância com os paradigmas preconizados pela reforma psiquiátrica, e não de acordo com os cânones tradicionais da doença mental, é imprescindível haver constantemente espaços de formação, discussão e potencialização dos trabalhadores. 


\section{Agradecimento}

Ao Conselho Nacional de Desenvolvimento Científico e Tecnológico (CNPq) e à Fundação de Amparo à Pesquisa do Estado de São Paulo (Fapesp) pelo financiamento da pesquisa de mestrado que deu origem a este trabalho.

\section{Colaboradores}

Camila Junqueira redigiu o artigo. Alberto Olavo Advincula Reis orientou a pesquisa e revisou o artigo. Modesto Leite Rolim Neto e Fabíola Zioni auxiliaram na elaboração da pesquisa e revisaram o artigo. Vicente Sarubbi Jr. trabalhou na revisão da literatura e discussão dos dados.

Resumen Esta investigación exploratoria, de carácter cualitativo, se centró en la narrativa de los profesionales de Centros de Atención Psicosocial para niños y adolescentes. El objetivo fue describir y analizar las trayectorias de trabajadores de estos centros y su relación con el proceso de inserción y práctica en este campo, así como comprender cómo esta trayectoria influye en el quehacer cotidiano de los profesionales. Se utilizó un cuestionario con preguntas abiertas y entrevistas narrativas. El universo de estudio comprendió ocho trabajadores de diferentes categorías profesionales, asignados a dos centros de atención psicosocial de niños y adolescentes, en el municipio de São Paulo, estado de São Paulo, Brasil; uno administrado directamente por la municipalidad y el otro, por una organización social de salud. Se observó que la vida política es poco citada por los trabajadores de la organización, mientras que para los profesionales de la municipalidad representa un importante sentido del trabajo. Todos los profesionales entrevistados guardan similitudes entre sí, entre ellas: la asimilación del tratamiento ofrecido a niños a los conceptos adultos, el pasaje por hospitales y consultorios en sus trayectorias y el foco de la mirada del profesional dirigido a la enfermedad y no al sujeto del sufrimiento. Prisioneros de estas representaciones, los profesionales viven competencias, habilidades y pensamientos que dan origen a la improvisación y la angustia.

Palabras clave salud pública; salud mental; infancia y adolescencia; asistencia a la salud. 


\title{
Notas
}

\author{
1 Programa de Pós-Graduação em Saúde Pública da Faculdade de Saúde Pública da \\ Universidade de São Paulo, São Paulo, Brasil. \\ <camilajmuylaert@usp.br> \\ Correspondência: Avenida Dr. Arnaldo, 715, sala 18, CEP 01246-904, São Paulo, São \\ Paulo, Brasil. \\ 2 Faculdade de Saúde Pública da Universidade de São Paulo, São Paulo, Brasil. \\ $<$ modestorolim@yahoo.com.br> \\ 3 Faculdade de Saúde Pública da Universidade de São Paulo, São Paulo, Brasil. \\ $<$ fabiolaz@usp.br> \\ 4 Faculdade de Saúde Pública da Universidade de São Paulo, São Paulo, Brasil. \\ $<$ vicente.sarubbi@usp.br> \\ 5 Departamento de Saúde Materno-Infantil, Faculdade de Saúde Pública da Universi- \\ dade de São Paulo, São Paulo, Brasil. \\ Doutor em Saúde Pública pela Universidade de São Paulo. \\ <albereis@usp.br>
}

\section{Referências}

AMARANTE, Paulo. Asilos, alienados, uma pequena história da psiquiatria no Brasil. In: AMARANTE, Paulo (org). Psiquiatria social e reforma psiquiátrica. Rio de Janeiro: Fiocruz, 1994, p. 73-84.

AMARANTE, Paulo. Ensaios: subjetividade, saúde mental, sociedade. Rio de Janeiro: Fiocruz, 2000.

BACHELARD, Gaston. A formação do espirito científico: contribuição para uma psicanálise do conhecimento. Rio de Janeiro: Contraponto, 1996.

BEZARRA JR., Benilton. Desafios da reforma psiquiátrica no Brasil. Physis: Revista de
Saúde Coletiva, Rio de Janeiro, v. 17, n. 2, 2007. Disponível em: <www.scielo.br/scielo. php? script $=$ sci_arttext $\&$ pid $=$ S0103$73312007000200002 \& \operatorname{lng}=\mathrm{en} \& \mathrm{nrm}=$ iso $>$. Acesso em: 22 jul. 2013.

BOURDIEU, Pierre. O poder simbólico. 15. ed. Rio de Janeiro: Bertrand Brasil, 2011.

BRASIL. Ministério da Saúde. Secretaria de Atenção à Saúde. Departamento de ações programáticas estratégicas. Caminhos para uma política de Saúde Mental Infantojuvenil. Brasília: Ministério da Saúde, 2005. Disponível em: <http://portal.saude.gov.br/portal/ arquivos/pdf/caminhos_infantojuv.pdf $>$. Acesso em: 22 jul. 2013. 
HIRDES, Alice; KANTORSKI, Luciane P. Reabilitação psicossocial: objetivos, princípios e valores. Revista de Enfermagem UERJ, Rio de Janeiro, v.12, n. 2. p. 217-221, 2004.

JOVCHELOVICH, Sandra; BAUER, Martin W. Entrevista narrativa. In: BAUER, Martin W.; GASKELL, George. Pesquisa qualitativa com texto, imagem e som: um manual prático. Petrópolis: Vozes, 2002. p. 90-113.

LIRA, Geison V.; CATRIB, Ana M. F.; NATIONS, Marilyn K. A narrativa na pesquisa social em saúde: perspectiva e método. $R e$ vista Brasileira em Promoção da Saúde (RBPS), Fortaleza, v. 16, n. 1/2, p. 59-66, 2003.

MARAZINA, Isabel V. Trabalhador de saúde mental: encruzilhada da loucura. Saúde e Loucura, n. 1. São Paulo: Hucitec, 1989.

NUNES, Mônica; JUCÁ, Vládia J.; VALENTIM, Carla P. B. Ações de saúde mental no Programa Saúde da Família: confluências e dissonâncias das práticas com os princípios das reformas psiquiátrica e sanitária. Cadernos de Saúde Pública, Rio de Janeiro, v. 23, n. 10, p. 2.375-2.384, 2007.
REIS, Alberto O. A. Os Centros de Atenção Psicossocial infantojuvenis no estado de São Paulo. 236 p. (Tese de Livre-docência) Faculdade de Saúde Pública da Universidade de São Paulo, São Paulo, 2010.

REIS, Alberto O. A; DELFINI, Patricia S. S; DOMBI-BARBOSA, Carolina; OLIVEIRA, Maria Fernanda A. P. B. Crianças e adolescentes em sofrimento psíquico atendidos nos Centros de Atenção Psicossocial Infantojuvenis. In: LAURIDSEN-RIBEIRO, Edith; TANAKA, Oswaldo Y. (org.). Atenção em saúde mental para crianças e adolescentes no SUS. São Paulo: Hucitec; 2010. p. 186-210.

VASCONCELOS, Maria D. Pierre Bourdieu: a herança sociológica. Educação e Sociedade, Campinas, v. 23, n. 78, p. 77-87, 2002. Disponível em: <www.scielo.br/scielo.php? script=sci_arttext\&pid=S0101-73302002000 200006\&lng $=$ en $\&$ nrm $=$ iso $>$. Acesso em: 22 jul. 2013.

Recebido em 26/09/2013

Aprovado em 20/08/2014 